\title{
CONSTRUÇÃO DE UM CAMPO SEMÂNTICO POR MEIO DE PRÁTICA ESPAÇADA EM ENSINO DE LÍNGUAS ADICIONAIS ONLINE
}

\author{
CONSTRUCTING A SEMANTIC FIELD THROUGH SPACED PRACTICE IN THE \\ TEACHING OF ADDITIONAL LANGUAGES ONLINE
}

\author{
Lúcia Rottava ${ }^{1}$, Antônio Márcio Da Silva ${ }^{2}$
}

\begin{abstract}
RESUMO: Este artigo foca na construção de campo semântico em algumas atividades relacionadas ao ensino de línguas adicionais por meio de tecnologias em tempo de isolamento social no Reino Unido. Por campo semântico entende-se como sendo uma das variáveis do contexto de situação, definido pela Linguística Sistêmico-Funcional de Halliday (1978), responsável pela construção da experiência do mundo que nos cerca e do mundo criado em nossa consciência como resultante das práticas sociais vivenciadas. $\mathrm{O}$ objetivo é analisar como o campo semântico é construído por meio de unidades temáticas que têm como propósito ensinar o conteúdo programático estabelecido para o ensino básico no Reino Unido. $\mathrm{O}$ artigo apresenta algumas tarefas e discute seu propósito e funcionalidade em atividades virtuais no ensino remoto e destaca a importância da "prática espaçada" como forma de ajudar os aprendizes na construção do conhecimento linguístico em termos de vocabulário, estruturas linguísticas e aspectos culturais que entram em jogo no campo semântico.
\end{abstract}

PALAVRAS-CHAVE: Campo semântico; prática espaçada; língua adicional; novas tecnologias; G-suite.

ABSTRACT: This article focuses on the construction of a semantic field in some activities related to the teaching of additional languages through technologies in times of social isolation in the United Kingdom. Semantic field is understood as being one of the variables of the context of situation, defined by Halliday's Systemic-Functional Linguistics (1978), responsible for the construction of the experience of the world around us and the world created in our consciousness as a result of the social practices we have experienced. The aim of this study is to analyse how the semantic field is constructed through thematic units that aim to teach the syllabus established for compulsory education in the United Kingdom. The article presents some tasks and discusses their purposes and functionality in online activities in remote education and highlights the importance of "spaced practice" as a way to help learners with the construction of linguistic knowledge in terms of vocabulary, linguistic structures, and cultural aspects that come into play within the semantic field.

KEYWORDS: Semantic field; spaced practice; additional language; new technologies; G-suite.

\section{Introdução}

O conhecimento em diversas áreas tem especificidades e características que lhe é inerente e varia de acordo com o campo, a situação de uso, o usuário e o propósito. Para falar de um determinado assunto, por exemplo, pandemia, não seria suficiente apenas saber o seu significado de

\footnotetext{
${ }^{1}$ Doutora em Linguística Aplicada pela Universidade Estadual de Campinas. Professora da Universidade Federal do Rio Grande do Sul.

${ }^{2}$ Professor e pesquisador independente, Reino Unido.
} 
modo isolado: que se trata de uma doença com abrangência mundial, que se opõe ao conceito de epidemia, e que tem impacto na população, mas também dependeria do conhecimento dos falantes.

O impacto semântico de cada palavra varia de acordo com o sentido que tal item do vocabulário é usado, por quem e com que propósito. Por exemplo, para o vocabulário pandemia, o sentido recorrente na área da saúde (médicos, enfermeiros, etc.) difere do uso feito por políticos, por economistas ou no cotidiano da população.

Situação análoga ocorre na aprendizagem de vocabulário por aprendizes de línguas adicionais. $\mathrm{O}$ vocabulário de um determinado campo do conhecimento precisa ser atualizado para que haja interação (SUMERACKI; WEINSTEIN, 2018; SMITH; CONTI, 2016; BOOTH, 2018) e então usados em outro campo com significado distinto. Ademais, o sentido construído varia do campo semântico (HALLIDAY; MATTHIESSEN, 2014) dos falantes que lhes permite usar a língua de acordo com as especificidades do contexto de situação: para dar conta da experiência do mundo que nos cerca e daquele criado em nossa consciência (campo); para estabelecer e manter relações sociais mediante os papéis sociais na interação entre distintos falantes, ao mesmo tempo em que serve para expressar atitudes, crenças (relações); para recorrer aos recursos da linguagem que permitem ao usuário construir textos (modo) (HALLIDAY, 1978). Dentre essas especificidades, o foco deste artigo é na primeira: campo semântico e sua relação com o ensino do vocabulário em contexto de ensino de línguas adicionais no Reino Unido.

Embora o ensino de vocabulário tenha recebido apenas uma orientação mais geral do que prescritiva em programas de ensino no Reino Unido (DFE, 2013; 2014), seu papel é indubitavelmente essencial para atender as expectativas de cada nível de ensino. O vocabulário é também a base para a construção de uma rede semântica de sentidos que vai constituir o repertório linguístico na língua adicional dos aprendizes e isso lhes permite interagir. Sob este olhar, referindo-se ao que propõe a Linguística Sistêmico-Funcional (SFL), tais expectativas significam que a comunicação varia de acordo com o "contexto de cultura" e o "contexto de situação", os quais têm sido particularmente enfatizados em discussões do campo semântico na construção do conhecimento.

Assim, propõe-se neste artigo compreender como um campo semântico pode ser construído em tarefas online que focam no ensino e posterior reciclagem de vocabulário por meio de "prática espaçada" (BIRD, 2010; CARPENTER et alii. 2009; SEABROOK et alii. 2005; SOBEL et alii. 2011). Em tais tarefas, o pressuposto metodológico subjacente é recuperar o vocabulário, passando 
a ser usado em contexto de situação distinto.

Este artigo está organizado em cinco seções, incluindo esta introdução. Na seção teórica, são definidos os conceitos de campo semântico, ensino/aprendizagem de vocabulário e a prática espaçada e seu impacto na reciclagem de vocabulário e na memória a longo prazo. Na seção referente aos apontamentos metodológicos são descritos o contexto e a natureza das tarefas. Na seção de análise de dados são apresentadas as tarefas e suas características em termos de prática espaçada que focam no aprendizado de vocabulário e, finalmente, são pontuadas as considerações finais.

\section{Base teórica}

\section{Campo semântico}

A Linguística Sistêmico-Funcional (SFL) é uma teoria semântica (HALLIDAY, 1978), e dela deriva o termo "campo semântico" (MARTIN, 2006, 2007a/b) o qual tem sido usado para se referir ao conhecimento a respeito de um determinado assunto ou tema. Para construir um campo semântico é necessário levar em conta o "contexto de cultura" e o "contexto de situação" no qual o texto é realizado, podendo ser oral ou escrito. Texto significa, nesse caso, a porção de língua usada para interagir; é o que tem um significado em um campo particular. No momento em que se desenha ou escreve algo, cria-se um campo semântico que representa nosso mundo, da linguagem cotidiana (por exemplo, em uma conversa com um amigo) e das situações mais formais (por exemplo, uma entrevista de emprego). Assim, à luz da SFL, está-se constantemente produzindo textos em contexto (MALINOWSKI, 1923; HALLIDAY, 1978).

O contexto situacional subjaz a todo e a qualquer uso da língua instanciado no texto; ele pressupõe que a linguagem/língua só existe aliada a um determinado contexto, que está sempre relacionado a uma situação (cenário) ou ato (ROTTAVA; DA SILVA, 2015). Qualquer que seja o assunto sobre o qual se fala, há necessidade de escolhas lexicais e/ou registros linguísticos que constituam um campo semântico e possibilitem a interação; isto é, recorre-se ao vocabulário para poder dizer ou escrever alguma coisa. No entanto, essa recorrência não é aleatória e as escolhas lexicais devem ser adequadas ao tema ou ao campo de conhecimento que está sendo tratado. Como Martin (2007a) argumenta, é preciso entender o discurso que contextualiza, muda ou recontextualiza o conhecimento.

Do mesmo modo, quando os falantes interagem, eles recorrem ao campo semântico que é 
experienciado ou vivenciado; em outras palavras, a interação ocorre através de um campo semântico existente. Assim, o argumento defendido é que esse campo semântico está sempre relacionado ao contexto da situação e, de fato, aos registros (formais/informais). Por exemplo, uma pessoa que organiza uma festa de aniversário não interage com os organizadores da mesma maneira que conversa com os convidados durante a festa sobre esse campo semântico. Outro exemplo seria o "convívio" em uma determinada língua adicional, usada apenas para viagens turísticas enquanto um país é visitado.

Portanto, cada campo semântico precisa ser adaptado a cada situação para falar sobre um "campo do conhecimento", para que a pessoa consiga interagir com um interlocutor e produzir discursos. Assim, é necessário o conhecimento de vários itens lexicais relacionados a um determinado campo do conhecimento para que a comunicação aconteça. Além disso, esses itens lexicais variam de acordo com quem é o interlocutor. Então, a questão seria como o campo semântico/conhecimento é construído. É pensando neste questionamento que a próxima seção aborda o ensino/aprendizagem do vocabulário por se constituir, do ponto de vista defendido neste artigo, o conhecimento necessário para construir um campo semântico.

\section{Ensino/aprendizagem de vocabulário}

O interesse no papel que o vocabulário exerce no ensino de línguas tem aumentado a partir dos anos 90 (HULSTIJN, 1992; LAUFER; SHMUELI, 1997; PRINCE, 1995) em virtude dos inúmeros estudos voltados ao seu ensino em sala de aula (AHMADI et alii. 2012; FOLSE, 2004; HUNT; BEGLAR, 2002; NAM, 2010; NATION, 2002; READ, 2004). De fato, como Folse (2004) coloca, "se os alunos não entendem uma parte considerável do vocabulário na língua que leem ou ouvem, então ela não é compreensível e, portanto, não pode ser útil para aquisição" (n.p. $)^{3}$. No entanto, há controvérsias no que diz respeito à maneira como o vocabulário poderia ser ensinado ou aprendido, visto que algumas pesquisas indicam que ele poderia ser ensinado incidentalmente, mas outras defendem uma aprendizagem intencional (SMITH; CONTI, 2016).

Bromley (2007) menciona a afirmação de Greenwood (2004), segundo a qual "existe uma grande divisão entre o que sabemos sobre o ensino de vocabulário e o que (muitas vezes ainda) fazemos" (2007, p. 528) ${ }^{4}$. Com a abordagem baseada em tarefas, certas maneiras de ensinar

\footnotetext{
${ }^{3}$ No original: "if learners do not understand a sizable portion of the vocabulary in the language that they are reading or hearing, then this language is not comprehensible and therefore cannot be useful for acquisition".

${ }^{4}$ No original: "There is a great divide between what we know about vocabulary instruction and what we (often, still)
} 
vocabulário, como por exemplo a memorização de listas de itens, foram vistas como obsoletas. No entanto, como Read (2004) argumenta, embora os alunos possam adquirir algum vocabulário de maneira incidental, "também é necessário um estudo mais direto e sistemático do vocabulário" (2004, p. 146) $)^{5}$ Essa visão é também compartilhada por Smith e Conti (2016), os quais afirmam que a instrução explícita do vocabulário é essencial para os alunos iniciantes, pois a falta de vocabulário "limita sua capacidade de leitura e compreensão" (p. 45) ${ }^{6}$. Portanto, para que os aprendizes possam interagir em uma língua adicional com certa adequação, precisam de um campo semântico que lhes permita tal interação. Como Read (2004) argumenta, os aprendizes percebem que as limitações em seu repertório de vocabulário podem "prejudicar sua capacidade de se comunicar efetivamente na língua-alvo" (p. 146) ${ }^{7}$. De fato, como Bromley coloca, o vocabulário é “um dos principais elementos para a compreensão, a fluência e o desempenho" $(2007,528)^{8}$.

Quanto ao vocabulário, Masoura e Gathercole (2005) recorrem a Laufer (1990) para compartilhar a ideia de que sua aquisição é crucial para determinar a competência na segunda língua. Apesar de haver divergências sobre abordagens incidentais e explícitas ao ensino do vocabulário, ambas poderiam contribuir para a aprendizagem de uma língua e, por conseguinte, para o ensino explícito do vocabulário. De fato, quando colocado no contexto de escolas no Reino Unido, onde a maioria dos currículos é dirigida por exames como o $\mathrm{GCSE}^{9}$, o ensino explícito de vocabulário parece predominar. Além disso, como resultado de um currículo amplo a ser ensinado, parece haver pouco espaço para práticas espaçadas e reciclagem de vocabulário além do previsto nos livros didáticos usados. Em outras palavras, esse conhecimento de vocabulário deriva possivelmente de oportunidades específicas para usar uma L2.

Para melhor compreender a construção de um campo semântico e sua relação com o ensino do vocabulário, na seção que segue, descrevem-se práticas espaçadas para a reciclagem de vocabulário que visam à retenção de itens lexicais na memória a longo prazo.

\footnotetext{
do."

${ }^{5}$ No original: "more direct and systematic study of vocabulary is also required"

${ }^{6}$ No original: "limits their reading and listening ability"

${ }^{7}$ No original: "hamper their ability to communicate effectively in the target language"

${ }^{8}$ No original: "a principle contributor to comprehension, fluency, and achievement"

${ }^{9} \mathrm{O}$ exame GCSE (General Certificate of Secondary Education/Certificado Geral de Educação Secundária) é uma qualificação (exame) que acontece no final da educação secundária e é prova da conclusão do ensino obrigatório no Reino Unido. Cada conteúdo (ou componente curricular) tem seu GCSE e funciona de forma independente. Há disciplinas que são obrigatórias e outras o aprendiz escolhe. O número de GCSEs, portanto, dependerá da escolha do aprendiz. Por exemplo, em relação a línguas adicionais, estas não são obrigatórias; porém, há estudantes que elegem duas ou mais línguas, especialmente alunos bilíngues (a língua dos pais, e outra língua oferecida na escola onde estudam).
} 


\section{Prática espaçada: impactos na reciclagem de vocabulário e na memória a longo prazo}

Prática espaçada diz respeito ao intervalo de tempo entre tarefas, ou seja, trata-se do "efeito de espaçamento" (CARPENTER, et alii 2012). Vários autores investigaram os benefícios da prática espaçada e os resultados de fato indicaram sua importância (BIRD, 2010; CARPENTER et alii. 2009; SEABROOK et alii. 2005; SOBEL et alii. 2011). De acordo com Carpenter et alii. (2012), a prática espaçada "geralmente produz melhor aprendizado do que gastar a mesma quantidade de tempo estudando o material em uma única sessão” (p. 370) ${ }^{10}$. Essa prática contrasta com a denominada "apresentação em massa", na qual "as coisas são estudadas repetidamente em um curto espaço de tempo" (SMITH; CONTI, 2016, p. 176) ${ }^{11}$. A Fig. 1 mostra uma representação visual das duas abordagens:

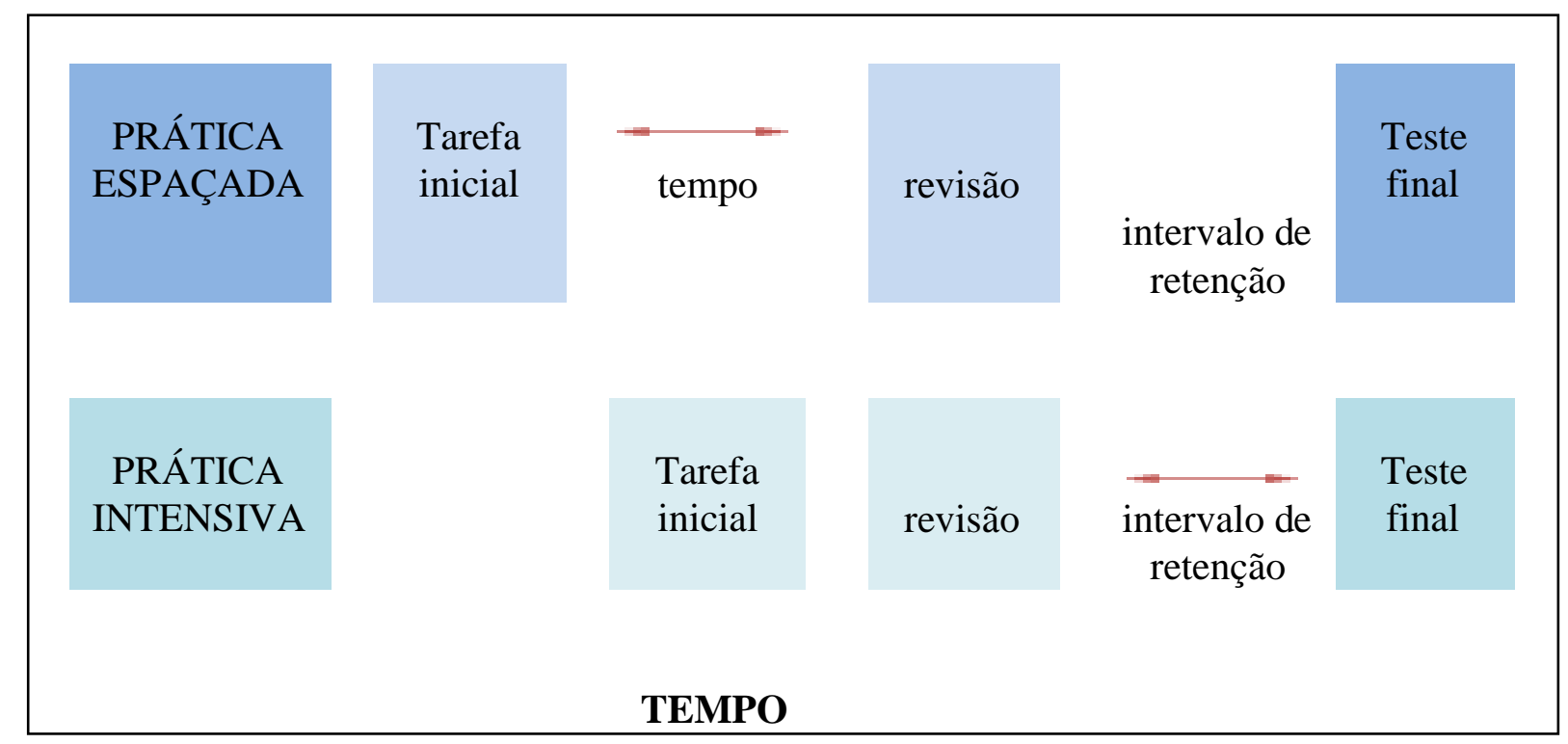

Fig. 1 - Efeito espaçamento (KANG, 2016)

Em relação ao papel da prática espaçada no ensino e aprendizagem do vocabulário, Folse (2004) afirma que o número de vezes que o aluno precisa rever uma palavra é essencial para a memória a longo prazo, o que pode ser facilitado por meio de atividades em sala de aula definidas pelo professor. De fato, como mostraram os estudos em psicologia cognitiva e educacional, a prática espaçada é capaz de produzir aprendizado superior a longo prazo quando comparada à prática intensiva (KANG, 2016). Tal prática permite aos aprendizes o

\footnotetext{
${ }^{10}$ No original: "often produces better learning than spending the same amount of time studying the material in a single session"

${ }^{11}$ No original: "things are studied repeatedly in a short span of time"
} 
acesso rápido a informações relevantes da memória, geralmente "pré-requisitos para aprendizado e raciocínio de ordem superior" (KANG, 2016, p. 13) ${ }^{12}$ e é viável para obter grandes resultados sem a necessidade de recursos extras (tempo ou dinheiro).

Uma questão que parece dificultar a ocorrência de práticas espaçadas e de reciclagem de vocabulário em aula é a maneira como os currículos são organizados. No entanto, eles podem ser otimizados "por meio do agendamento da revisão ou prática” (KANG, 2016: 12) ${ }^{13}$.

No que tange à reciclagem de vocabulário, Ellis e Beaton (1993) veem a múltipla exposição como uma estratégia para aprender enquanto uma palavra é produzida em um contexto. As múltiplas exposições ao significado de uma palavra são essenciais para aprendizagem eficaz do vocabulário (NATIONAL READING PANEL, 2000) e, como expõe Stahl (2005), o aprendiz precisa ver uma palavra mais de uma vez para colocá-la efetivamente na memória a longo prazo. No entanto, Stahl também adverte que isso não deve ser assumido como repetição sem sentido ou simples listagem de palavras, mas ser oferecidas aos alunos oportunidades de ver o vocabulário aprendido sendo implementado em vários contextos e apresentado de maneiras diferentes. De fato, essa percepção já havia sido pontuada por Nation (2001) ao afirmar que "os contextos de uso estão associados a diferentes processos cognitivos durante o aprendizado de línguas" (p. 80) ${ }^{14}$.

É reconhecida que a prática de recuperação ou reciclagem melhora o aprendizado dos alunos. Tal afirmação é respaldada por Sumeracki e Weinstein (2018) ao sugerir que essa prática é uma parte importante da aula, independentemente da abordagem de ensino, e pode ocorrer na compreensão e produção (oral/escrita). Sua importância se situa no fato de que os aprendizes têm mais probabilidade de esquecer o vocabulário ensinado sem passar por prática espaçada (SMITH; CONTI, 2016). Portanto, mais importante do que ensinar vocabulário é garantir que as palavras ensinadas/aprendidas sejam facilmente acessíveis mais tarde na memória a longo prazo, o que pode ser facilitado através de práticas espaçadas.

No entanto, Smith e Conti (2016) argumentam que não basta construir uma memória, mas é preciso aprofundar a "conexão sináptica", visto a memória ser ativada várias vezes. A esse respeito, referindo-se a vários estudos sobre memória, Booth (2018) menciona especificamente pesquisas recentes que abordaram a memória a longo prazo e mostraram

\footnotetext{
${ }^{12}$ No original: "prerequisites for higher order learning and reasoning"

${ }^{13}$ No original: "via the scheduling of review or practice"

${ }^{14}$ No original: "contexts-of-use are associated with different cognitive processes during language learning"
} 
uma tendência a enfraquecer caso seja deixada sem reativação por um período de tempo. Essa visão contraria pesquisas anteriores que afirmavam que algo armazenado na memória de longo prazo estaria lá para sempre (BOOTH, 2018). Para evitar o esquecimento, Booth (2018) diz que não apenas novas informações precisam ser introduzidas em pequenas quantidades, mas também sejam recorrentes para que possam ser armazenadas na memória de longo prazo. De fato, pesquisas demonstram que "a construção mais bem-sucedida de uma memória ocorre quando um novo conteúdo é vinculado ao conhecimento prévio" (SMITH; CONTI, 2016, p. 46) ${ }^{15}$, visto que a retenção de novas informações é de fato determinada por sua qualidade e frequência no processamento de atividades (READ, 2004).

Portanto, é importante considerar as informações recebidas pelos alunos, a frequência que elas são recuperadas e o modo para ajudar os aprendizes a melhorarem sua memória a longo prazo por meio de reativação. Por sua vez, essa reativação vai criando "campos semânticos" e sendo constantemente acessível aos aprendizes por meio de práticas espaçadas.

\section{Alguns apontamentos metodológicos}

O contexto institucional e escolar a que se destinam as tarefas planejadas, objeto de análise, é de ensino de língua adicional, via tecnologia. Trata-se de uma escola regular localizada em uma grande cidade do Reino Unido, e as tarefas foram propostas em período de pandemia na primeira metade de 2020.

O Currículo Nacional do Reino Unido foca no ensino do vocabulário que parte de situações familiares e rotineiras para então propiciar aos aprendizes uma base sólida para interagir em temas práticos de vivências em comunidade ou sociedade, nas quais o vocabulário do aprendiz se amplia de modo que os ajuda a ir além de usar conceitos que expressam necessidades e interesses imediatos e desenvolver sua espontaneidade e fluência quando interagem na língua adicional. Em tais casos, ele precisa usar vocabulário abrangente e aprofundado (DfE, 2014), que então será consolidado em contexto de uso da língua, organizado de acordo com temas inerentes às situações de vida real, em níveis local, nacional, internacional e global.

Para situar melhor o lugar e o espaço que línguas adicionais têm nesse país, o ensino

\footnotetext{
${ }^{15}$ No original: "the most successful construction of a memory takes place when new content is linked to prior knowledge"
} 
está assim organizado: fase de ensino primária ( $1^{\circ}$. ao $6^{\circ}$. anos escolares); fase secundária ( $7^{\circ}$. ao $11^{\circ}$. anos escolares). O Currículo escolar para línguas adicionais prevê a oferta obrigatória de uma língua a partir do terceiro ano até o nono ano de escolaridade. As línguas comumente ofertadas incluem alemão, francês e espanhol. Além dessas línguas adicionais, há escolas que oferecem mandarim, italiano, russo ou uma língua da comunidade local, como o hindi.

Para tanto, as referidas tarefas foram propostas via recursos tecnológicos, em virtude do isolamento social. A utilização desses recursos contemplou principalmente a tecnologia disponível pelas extensões oferecidas pelo Google (tais como Google classroom, Google slides, Google sheets) e outras ferramentas disponíveis na web (como Screencastify, Vocaroo, Bitmoji), porém tudo foi apresentado por meio do Google classroom por ser de fato o recurso a que todos os alunos têm acesso gratuito e fácil desde que tenham também acesso à internet.

O Google classroom é a plataforma virtual (VLE) disponibilizada pelo Google como uma de suas extensões. Nessa plataforma, é possível postar materiais para os alunos, desenvolver chats, criar testes, dentre outras tantas funções. Cada aula é postada na ordem das tarefas a serem desenvolvidas. Inicia-se dando as instruções por meio de uma apresentação em Google slides sob o formato de uma sala virtual. Em cada slide, o aprendiz tem a informação que necessita para completar a atividade que está na lista no Google classroom.

A sala de aula virtual organiza-se em orientações centrais para desenvolver as aulas em circunstâncias vigentes. A Fig. 2 mostra a primeira página da sala de aula virtual e dela, derivam-se outras, dependendo do foco temático ou do conteúdo linguístico-gramatical das aulas. 


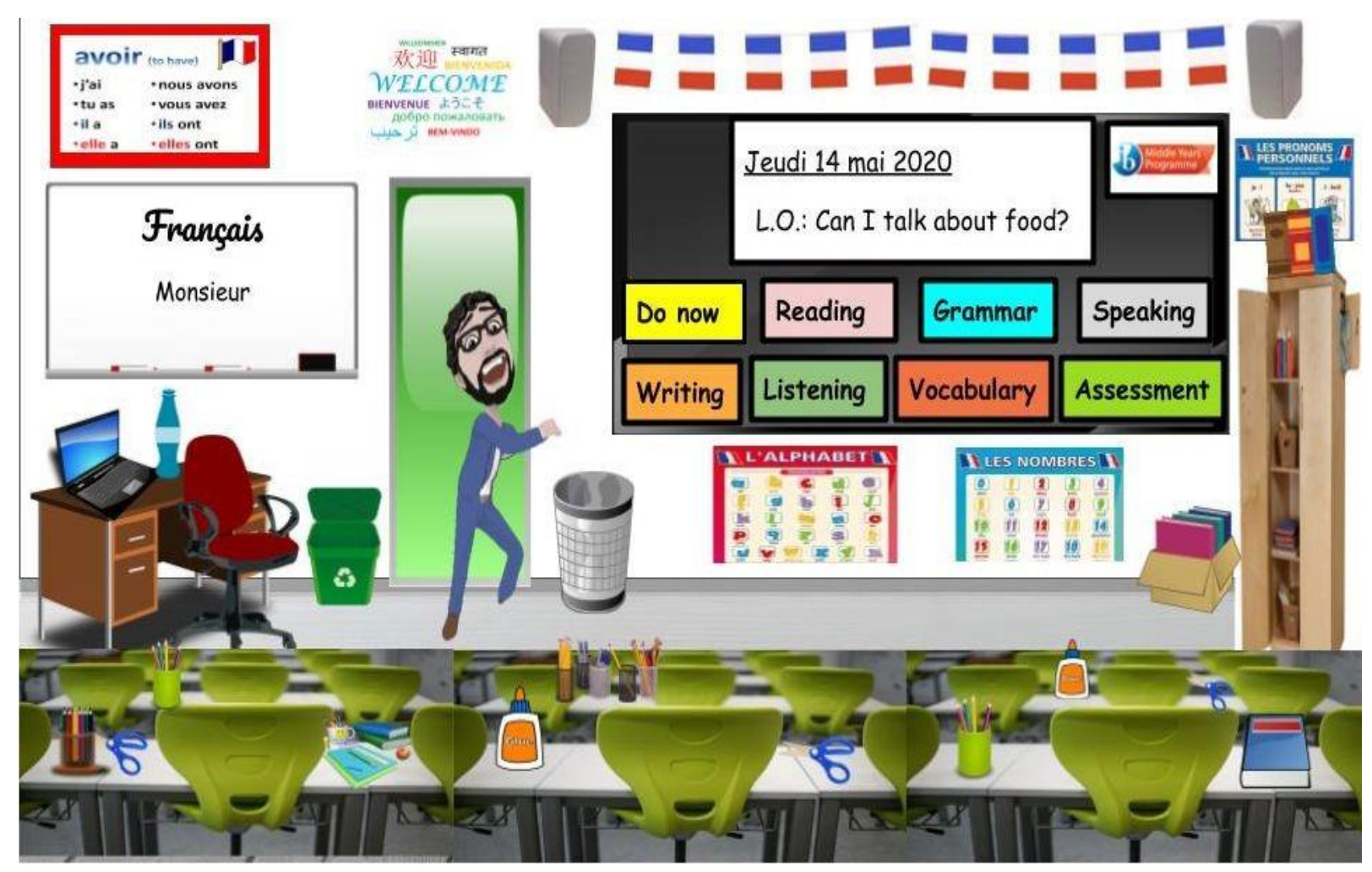

Fig. 2 - sala de aula virtual

Dessa tela inicial, são organizadas as tarefas. O corpus usado para ilustrar a discussão empreendida neste artigo consiste de uma unidade temática de um curso de francês língua adicional para o segundo ano escolar do ensino secundário, ou oitavo ano de escolarização. Ressalta-se que parte do programa de ensino para a referida turma havia sido previamente abordada em sala de aula. Dentre os conteúdos temáticos previamente abordados, contemplaram-se tópicos previstos pelo GCSE (orientados por temáticas ${ }^{16}$ ). Portanto, a recorrência à prática espaçada permitiu revisar conhecimento prévio e possibilitar aos aprendizes reciclar vocabulário.

\section{As tarefas e suas características}

Nesta seção serão trazidos exemplos para ilustrar a possibilidade de desenvolvimento de tarefas que permitam aos aprendizes recorrerem ao vocabulário já aprendido instrucional e incidentalmente para então com outros recursos virtuais usar esse conhecimento e construir

\footnotetext{
${ }^{16}$ As temáticas estão listadas no documento oficial, disponível em: https://www.aqa.org.uk/subjects/languages/gcse/french-8658. Acesso em 26 de maio de 2020.
} 
campos semânticos que preveem prática espaçada. Para tanto, a Fig. 3 mostra os diferentes

ambientes à disposição e de cada uma das "salas virtuais" relacionados às tarefas e às habilidades específicas. ${ }^{17{ }^{17}}$ A sequência dos slides na sala virtual orienta não apenas a execução das tarefas, mas cada unidade de trabalho proposta que permitiu que os aprendizes construíssem campos semânticos de conhecimento; dentre esses campos, estão aqueles ligados à necessidade imediata para interagir com o outro por meio, por exemplo, do vocabulário, leitura, recorrendo-se a músicas, filmes, dentre outros materiais disponíveis no Youtube.

Fig. 3 - ambientes da sala de aula virtual
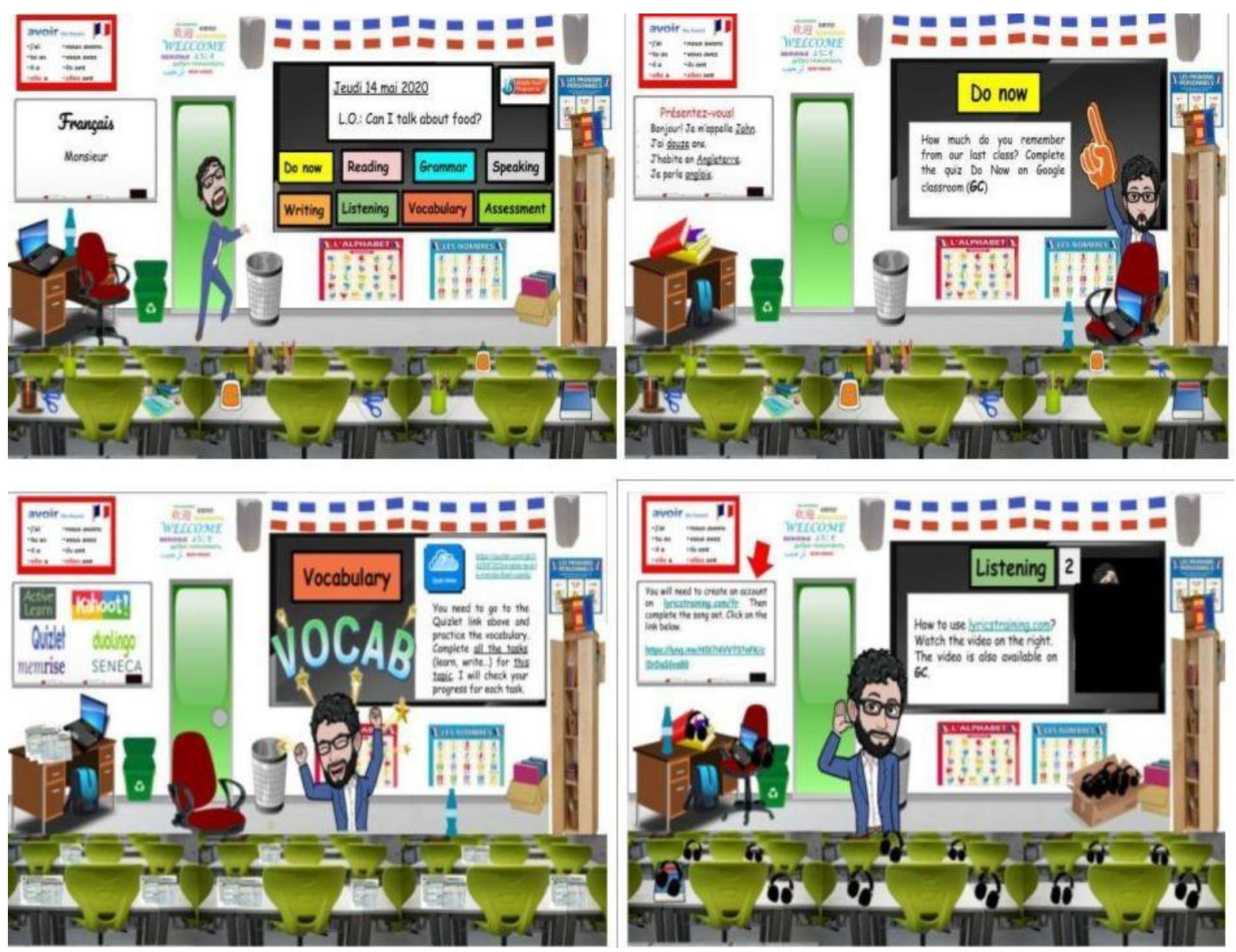

Dentre as temáticas desenvolvidas no "Term"/período (em média seis semanas de aula) ${ }^{18}$, são mencionados temas relacionados à alimentação: "comidas e bebidas" (como adquirir produtos e falar de um evento cultural relacionado a esse tópico). Essa temática foi desenvolvida a partir da terceira semana, num total de cinco. Salienta-se, no entanto, que as temáticas têm certa recursividade prevista pelos próprios programas de ensino e constam de

\footnotetext{
${ }^{17}$ Para criar a sala de aula virtual foram usados os recursos Google slides, Bitmoji, Google pictures, Snapchat e FunFace.

${ }^{18} \mathrm{O}$ ano escolar no Reino Unido é dividido em 6 "terms" (ou períodos) que variam entre 5 e 7 semanas.
} 
propósitos distintos em anos escolares anteriores ao oitavo ano, foco neste artigo.

Particularmente no oitavo ano, a temática se propõe a construir campo semântico, reciclando vocabulário, desta vez, porém, referindo-se a usos em contextos variados e visando à descrição de ações relacionadas à diversidade de tipos de alimentação, bebidas, compras de alimentos e oferecimento de pontos de vista a respeito da temática. Sobretudo, essa natureza recursiva das temáticas permite que se considere abordar o vocabulário recorrendo-se à prática espaçada. Para além da temática, linguisticamente é recorrente oferecer oportunidades para que os alunos usem o adjetivo partitivo.

Portanto, a primeira parte da temática a ser explorada foi a partir da revisão do vocabulário relativo à alimentação. Nesta revisão, contemplaram-se também aspectos linguísticos da língua (dimensão morfossintática no uso dos partitivos) para retomar o vocabulário relativo ao tema. Essa retomada permitiu igualmente obter informações quanto ao conhecimento prévio dos aprendizes sobre a temática e verificar a retenção deste campo semântico e ativá-lo na memória a longo prazo.

O ponto de partida para a tarefa foi um vídeo sobre o tema, focando em aspectos linguísticos, recorrendo-se ao uso de Screencastify ${ }^{19}$ para ativar o tema. Os alunos então tiveram que completar os exercícios em forma de Quizzes, no Google Forms, e enviar para o professor. De posse dessas informações, o professor planejou a sequência de tarefas online e as mesmas foram desenvolvidas de maneira que os aprendizes pudessem praticar e usar este campo semântico em diferentes contextos, receptiva (leitura e compreensão oral) e ativamente (produção oral).

Focando na prática espaçada, duas tarefas de compreensão oral foram propostas. A primeira tem foco no reconhecimento do vocabulário pela compreensão oral (Fig.4). Metodologicamente, o aprendiz é orientado a ouvir o áudio contendo quatro diferentes pessoas falando sobre comidas e bebidas que consumem em cada refeição. Nessa tarefa de compreensão oral, busca-se ativar outro campo semântico relativo às refeições (café da manhã, almoço, janta).

\footnotetext{
${ }^{19}$ O Screencastify é um software de gravação de vídeos da tela compatível com o Chrome. Com este software pode-se desfrutar de vídeos com qualidade rica e usufruir de atividades nas abas do navegador e a partir de sinais de áudio. Disponível em:

https://filmora.wondershare.com/pt-br/screen-recorder/how-to-use-screencastify.html. Acesso em 26 de maio de 2020 .
} 



Fig. 4 - tarefa de compreensão oral

$\mathrm{Na}$ segunda tarefa de compreensão oral, combinou-se a temática ao domínio linguístico para direcionar a atenção às unidades de medida (quilograma, pacote, etc.) (Fig. 5). Em outras palavras, os aprendizes puderam perceber a interconexão do vocabulário sobre a temática e o conhecimento linguístico, usado com recortes semânticos específicos e recorrentes em contexto da vida real.

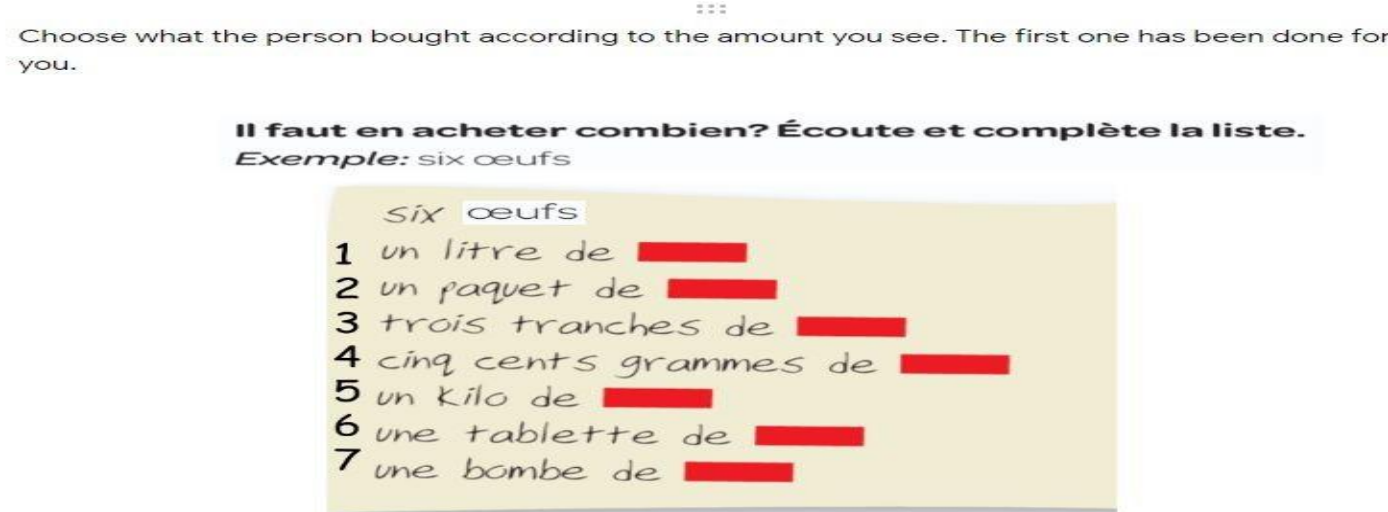

\footnotetext{
1. un litre de *

1. lait

2. farine
}

Fig. 5 - tarefa de compreensão oral 
Portanto, tarefas como estas permitem que um ou vários campos semânticos sejam reciclados de uma forma significativa e mostram ao aprendiz a conexão entre o que aprende e práticas que requerem mostrar o uso da língua.

Assim como na compreensão oral, a leitura proporciona ao aprendiz ver a aplicação do vocabulário aprendido em um contexto de uso autêntico, possibilitando articular ensino intencional com a aprendizagem incidental com a exigência de deslocar vocabulário já aprendido para campo semântico que está sendo veiculado nas tarefas.

A tarefa de leitura seguinte ilustra isso (Fig. 6) e foi planejada contendo quatro textos curtos, nos quais cada pessoa fala sobre hábitos alimentares (preferência de comida e bebida, por exemplo) em um contexto autêntico. O primeiro texto descreve o que integrantes da família gostam, a rotina de casa durante as refeições: entrada, o prato principal e sobremesa. O conjunto dos textos atualiza diferentes contextos e usos do vocabulário referente à alimentação. Dessa tarefa, os aprendizes terão subsídios lexicais e gramaticais para posterior tarefa escrita sobre esse mesmo tema.

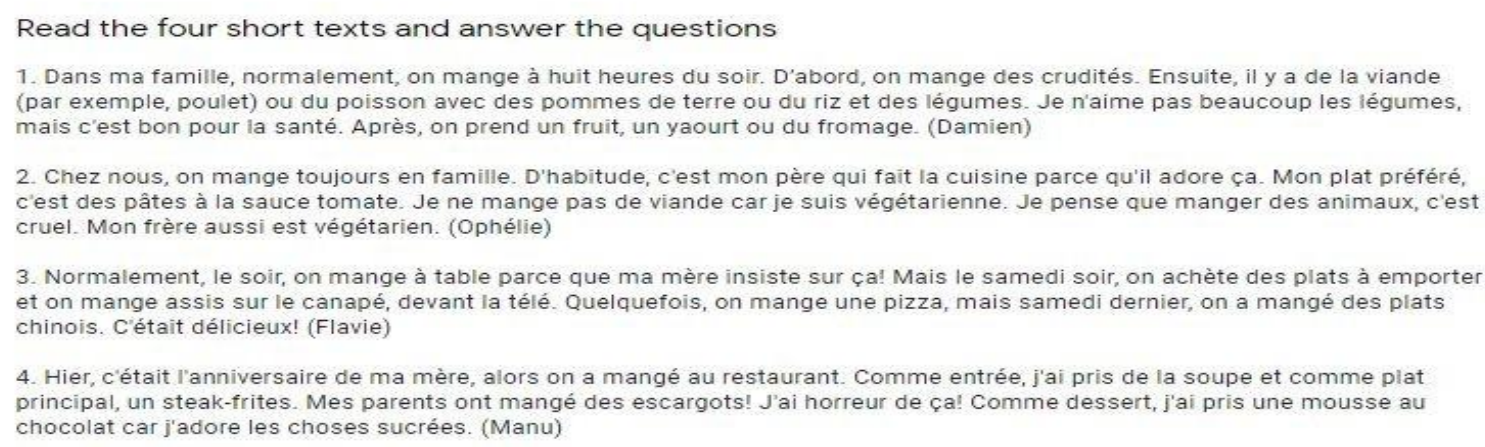

1. Dans ma famille, normalement, on mange à huit heures du soir. D'abord, on mange des crudités. Ensuite, il y a de la viande (par exemple, poulet) ou du poisson avec des pommes de terre ou du riz et des légumes. Je n'aime pas beaucoup les légumes, mais c'est bon pour la santé. Après, on prend un fruit, un yaourt ou du fromage. (Damien)

2. Chez nous, on mange toujours en famille. D'habitude, c'est mon père qui fait la cuisine parce qu'il adore ça. Mon plat préféré, c'est des pâtes à la sauce tomate. Je ne mange pas de viande car je suis végétarienne. Je pense que manger des animaux, c'est cruel. Mon frère aussi est végétarien. (Ophélie)

3. Normalement, le soir, on mange à table parce que ma mère insiste sur ça! Mais le samedi soir, on achète cles plats à emporter et on mange assis sur le canapé, devant la télé. Quelquefois, on mange une pizza, mais samedi dernier, on a mangé des plats chinois. C'était délicieux! (Flavie)

4. Hier, c'était l'anniversaire de ma mère, alors on a mangé au restaurant. Comme entrée, j'ai pris de la soupe et comme plat principal, un steak-frites. Mes parents ont mangé des escargots! J'ai horreur de ça! Comme dessert, j'ai pris une mousse au chocolat car j'adore les choses sucrées. (Manu)

What is the best caption for text 1 ? *

No meat for me, please!1

Dinner at eight.

A special meal out

Saturday night, takeaway night.

Fíg. 6 - tarefa de leitura

Assim, as diferentes tarefas permitem que os aprendizes sejam expostos à prática espaçada de modo que permita reativar conhecimento por meio da reciclagem de vocabulário. Nesta prática, uma semana após o tema ser introduzido, o campo semântico relativo à 
alimentação também é abordado em atividade lúdica. Para tanto, os aprendizes recebem umdocumento no formato de Google Slide por meio da Google Classroom. Na atividade, eles veem vários produtos e devem separá-los em quatro cestas de acordo com o adjetivo partitivo que é usado com cada um (Fig. 7).

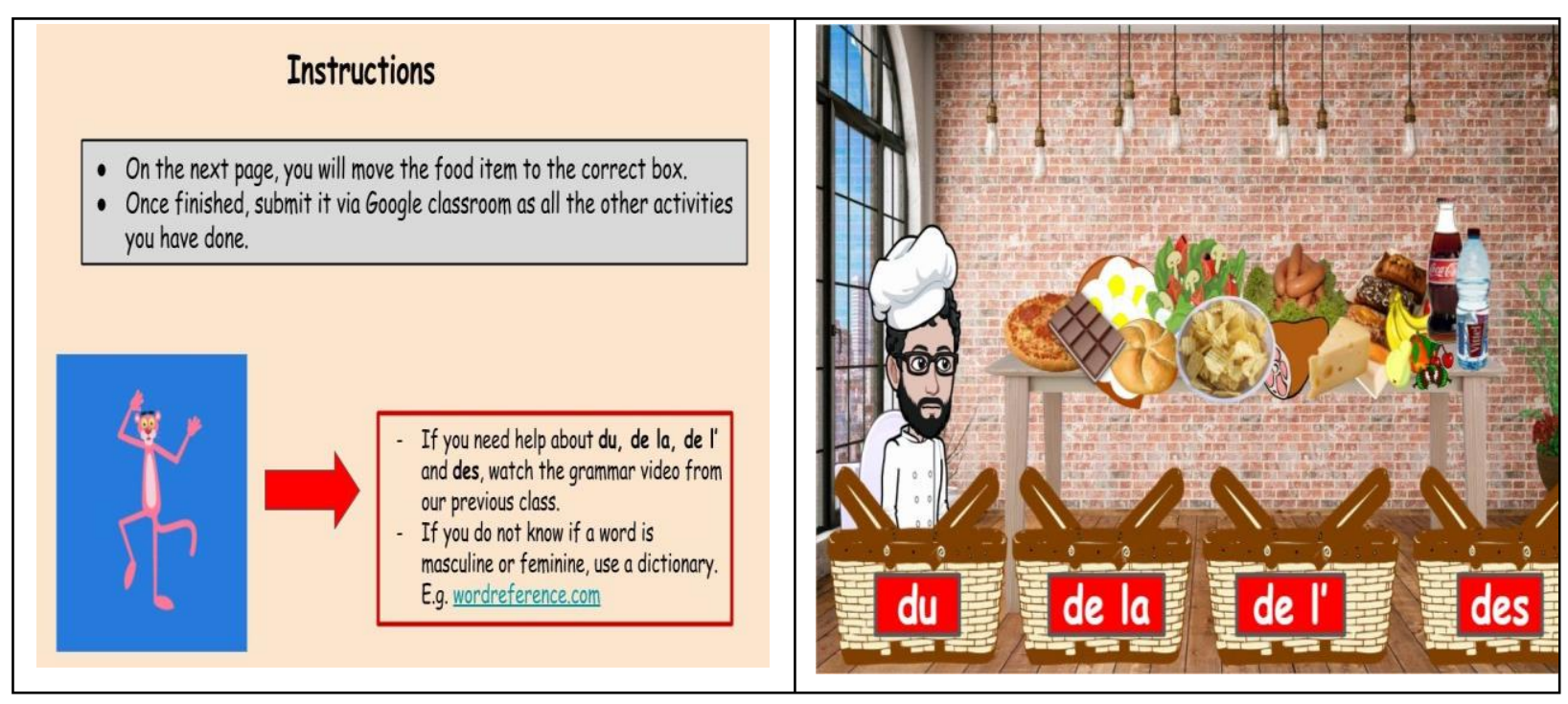

Fig. 7 - tarefa lúdica

Nesta tarefa, solicitou-se que os aprendizes relembrassem os nomes para cada um dos itens na língua adicional (aspectos morfológicos - gênero e número). Apesar de inicialmente parecer que se trata de uma abordagem apenas gramatical, trata-se de uma possibilidade para que os aprendizes construam um campo semântico com vocabulário e conhecimento da língua até então vistos em outros momentos do curso, desta vez, porém, com uma configuração virtual, e com propósito e interlocutor diversos.

Para o professor, por sua vez, o uso desse recurso tecnológico permitiu oferecer retorno (feedback) aos aprendizes e, portanto, ter a seu dispor resultados para planejar os próximos passos, dar continuidade às aulas e fazer com que os aprendizes se mantivessem motivados.

Finalmente, os dois últimos exemplos contemplam a produção oral, uma habilidade que se revelou desafiante durante o fechamento das escolas devido à pandemia e para a qual foram necessárias estratégias para elaborar e implementar as tarefas. Para tanto, , duas tarefas ilustram como se operacionaliza o conceito de reciclagem de vocabulário, abordada na parte teórica, conforme Fig. 8: 


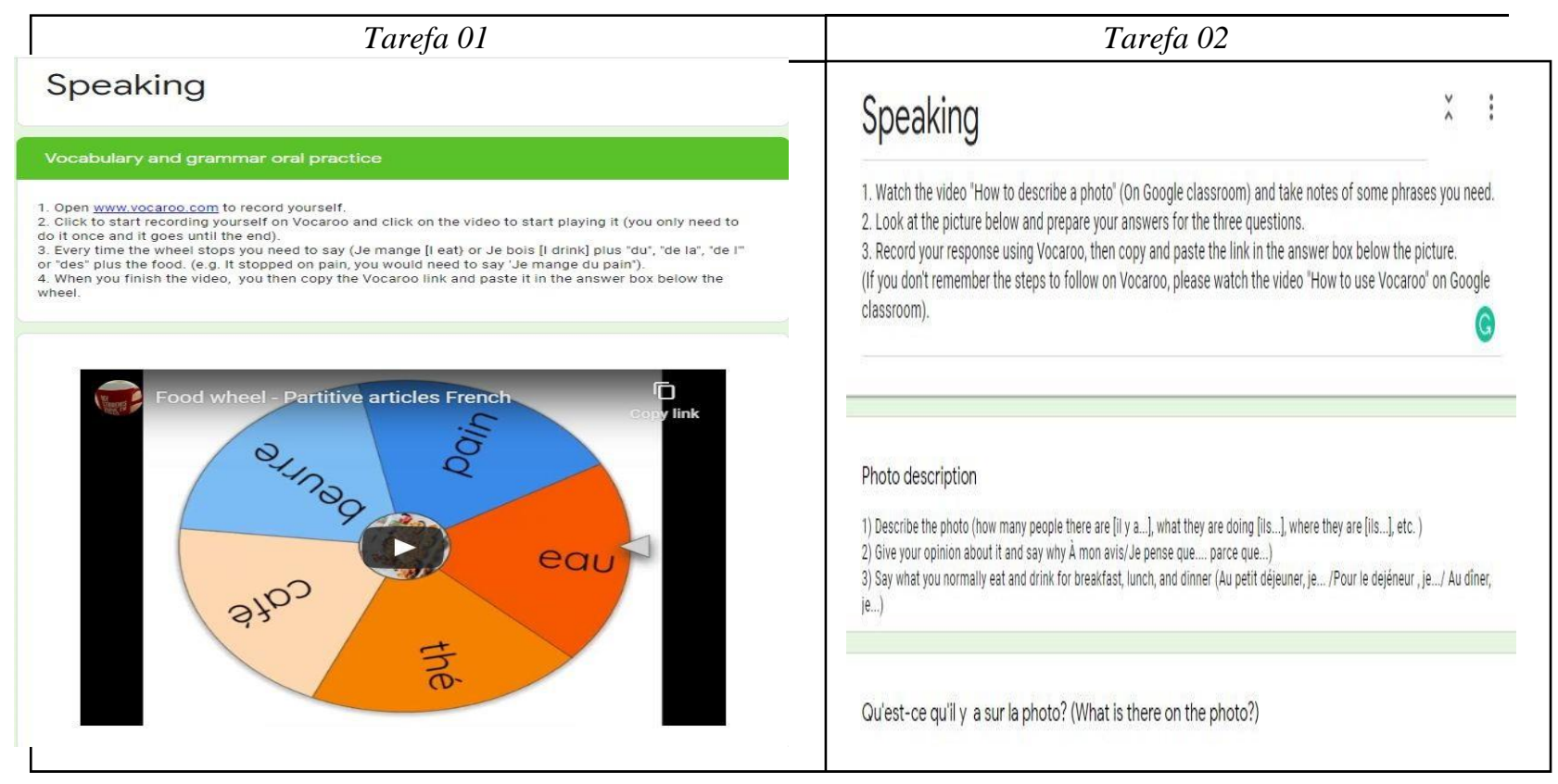

Fig. 8 - tarefas de produção oral

A tarefa 01 foi elaborada com o recurso Wheelofnames ${ }^{20}$ contendo nomes de comidas e de bebidas. Os aprendizes tinham que usar um recurso para gravação oral, neste caso o Vocaroo $^{21}$ e cada vez que o vídeo parava na comida ou bebida, eles tinham que gravar dizendo o nome da referida comida ou bebida que constava no recurso, buscando também usar o recurso linguístico adequado que antecede cada item lexical. Neste caso, vários desafios foram apresentados: recordar o que significava cada nome e adequá-lo morfologicamente e em tempo cronometrado.

A tarefa 2 foi baseada em exemplos de questões do exame oral no GCSE; os aprendizes precisavam descrever uma foto que continha uma família à mesa em suas refeições. Para realizá-la, tiveram que ativar o uso da língua em termos de vocabulário e gramática, assim como outros campos semânticos. Ademais de descrever e dar opinião sobre a foto (elementos esperados nesta tarefa no exame GCSE), os aprendizes falariam sobre si, do que comiam e bebiam em cada refeição. Após terminar a tarefa, cada aluno postava o link da gravação na mesma página da atividade para receber feedback do professor. Portanto, entre um período ("term" no calendário escolar no Reino Unido) e outro, o aprendiz pôde reciclar

\footnotetext{
${ }^{20}$ Disponível em: https://wheelofnames.com/ . Acesso em 15 de abril de 2020.

${ }^{21}$ Trata-se de uma ferramenta que permite gravações orais. Disponível em: https://vocaroo.com/. Acesso em $30 \mathrm{de}$ abril de 2020.
} 
vocabulário referente a campos semânticos aprendidos previamente e usá-los para produção oral de forma independente.

\section{Considerações finais}

Este artigo contemplou o conceito de campo semântico e explorou a possibilidade de introdução e aprendizagem de vocabulário com base em abordagem metodológica denominada prática espaçada. Para tanto, objetivou analisar como o campo semântico é construído por meio de unidades temáticas.

A principal variável interveniente neste estudo foi o fato de as tarefas serem desenvolvidas para serem implementadas em ambiente virtual em decorrência da pandemia de 2020. Tal fato requereu a construção de uma sala de aula virtual e dela derivaram-se as tarefas - de compreensão e produção oral, compreensão escrita, tarefa lúdica, articulando-se a temática central, alimentação, aos aspectos linguístico-gramaticais para ser a base para a aprendizagem da língua adicional.

As tarefas apresentadas, seguindo uma prática espaçada, representaram oportunidades diversificadas para ajudar os aprendizes a construir vários campos semânticos, sempre considerando o contexto de situação de uso e, de fato, estratégias para retenção de vocabulário. De fato, o pressuposto subjacente e orientador dessa prática pretendeu oportunizar tarefas que permitissem aos aprendizes obter domínio de um campo de conhecimento, tendo em mente que o aprendizado não é tão completo quanto se pode pensar (WILLINGHAM, 2008-2009) ou não se dá ou se concretiza de uma única vez. De fato, práticas que são espaçadas e se desenvolvem ao longo do tempo parecem ser mais relevantes, bem como parecem ajudar os alunos a desenvolver maneiras de lembrar e acessar informações da memória de longo prazo. Se pensarmos como essa prática é sugerida em materiais didáticos disponíveis, dentre eles livros didáticos, pode-se verificar que embora muitos livros adotados pelas escolas tendam a revisar vocabulário aprendido - livros geralmente organizados no formato de um "currículo espiral" -, isso pode ocorrer em um intervalo de tempo distante do momento em que o conteúdo fora apresentado pela primeira vez. Isso pode significar que os alunos terão esquecido certos campos do conhecimento, requerendo que parte do vocabulário talvez precise ser novamente ensinada (SMITH; CONTI, 2016). 
Por fim, em tempos de pandemia, o processo de ensino e aprendizagem teve que, mesmo temporariamente, lidar com outra realidade e recorrer a ferramentas virtuais disponíveis. Tais recursos têm permitido a exploração da prática espaçada com revisão de conteúdos anteriores de diferentes formas para que o aprendiz passe a usar o conteúdo aprendido em contextos situacionais diversos.

\section{REFERÊNCIAS}

AHMADI, Mohammad Reza et alii. Improving Vocabulary Learning in Foreign Language Learning Through Reciprocal Teaching Strategy. International Journal of Learning \& Development. n. 2, v. 6, p. 186-201, 2012.

BIRD, S. Effects of distributed practice on the acquisition of second language English syntax. Applied PsychoLinguistics, v.31, p. 635-650, 2010.

BOOTH, Nicky. What does research say about memory, and what can we do to enhance long-term learning in the classroom? Impact: Journal of the Chartered College of Teaching. 2018. Disponível em:

htps://impact.chartered.college/article/booth-research-memory-learning-classroom/Acesso em $20 \mathrm{de}$ março de 2020.

BROMLEY, Karen. Nine things every teacher should know about words and vocabulary instruction. International Reading Association. n.50, v. 7, 2007.

CARPENTER, Shana K.; et alii. Using Spacing to Enhance Diverse Forms of Learning: Review of Recent Research and Implications for Instruction. Educational Psychology Review. v.24, p. 369$378,2012$.

CARPENTER, Shana K.; et alii. Using tests to enhance 8th grade students' retention of US history facts. Applied Cognitive Psychology. v. 23, p. 760-771, 2009.

DfE. Department for Education. The national curriculum in England: Key stages 3 and 4 Framework Document. 2014. Disponível em: http://www.gov.uk/dfe/nationalcurriculum. Acesso em 25 de maio de 2020.

DfE. Department for Education. The National Curriculum in England: languages programmes of Study. 2013. Disponível em:

$\mathrm{h}$ ttps://www.gov.uk/government/publications/national-curriculum-in-england-languages-prog a mmes-of-study/national-curriculum-in-england-languages-progammes-of-study. Acesso em 25 de maio de 2020.

ELLIS, Nick; BEATON, Alan. Factors Affecting the Learning of Foreign Language Vocabulary: Imagery Keyword Mediators and Phonological Short-term Memory. The Quarterly Journal of Experimental Psychology. n. 4, v. 3, p. 533-558, 1993.

ELLIS, Rod. Principles of instructed language learning. System. v. 33, p. 209-224, 2005. 
FOLSE, Keith S. The Underestimated Importance of Vocabulary in the Foreign Language Classroom. 2004. Disponível em:

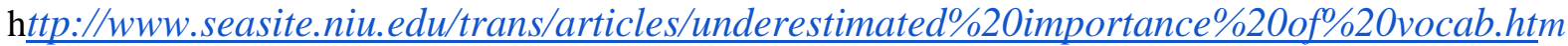

Acesso em 20 de maio de 2020;

HALLIDAY, M. A. K. Language as a social semiotic: The social interpretation of language and meaning. London: Edward Arnold, 1978.

HALliDAY, M. A. K.; MATTHIESSEN, C. An Introduction to Functional Grammar. 4a. ed. London: Arnold. 2014.

HULSTIJN, J. Retention of inferred and given word meanings: Experiments in incidental vocabulary learning. In: P. Arnaud \&: H. Bejoint (Eds.), Vocabulary and Applied Linguistics. London: Macmillan Academic and Professional Limited. 1992, p. 113-125.

HUNT, Alan; BEGLAR, David. Current Research and Practice in Teaching Vocabulary. In: Jack C. Richards; Willy A. Renandya (Eeds.).Methodology in language teaching: An anthology of current practice. Cambridge: Cambridge University Press.2002, p. 258-266.

KANG, Sean H. K. Spaced Repetition Promotes Efficient and Effective Learning: Policy Implications for Instruction. Behavioral and Brain Sciences. n. 3, v. 1, p. 12-19, 2016.

LAUFER, B., \&: SHMUELI, K. Memorizing new words: Does teaching have anything to do with it? RELC Journal. n. 28, v. 1, p. 89-108, 1997.

MALINOWSKI, Bronislaw. The Problem of Meaning in Primitive Languages. Supplement I in C.K. Ogden and I.A. Richards (of the 10th ed. (1972), p. 296-336, 1923.

MARTIN, J. R. Construing knowledge: A functional linguistic perspective. In: F. Christie; J.

R. Martin (Eds.), Language, knowledge and pedagogy. London: Continuum, 2007a.

MARTIN, J. R. Genre and Field: social processes and knowledge structures in systemic functional semiotics. In: 33rd International Systemic Functional Congress. Sydney: University of Sydney, 2006.

MARTIN, R., D. Genre Relations: Mapping Culture. London: Equinox, 2007b.

MASOURA, E V.; GATHERCOLE, S. E. Contrasting contributions of phonological short-term memory and long-term knowledge to vocabulary learning in a foreign language. Memory. n. 13, v. 3-4, p. 422-9, 2005.

NAM, Jihyun. Linking Research and Practice: Effective Strategies for Teaching Vocabulary in the ESL Classroom. TESL Canada Journal/Revue TESL du Canada. v. 28, n. 1, Winter, 2010.

NATION, I. S. P. Learning vocabulary in another language. Cambridge: Cambridge University Press, 2001.

NATION, Paul. 'Best practice in vocabulary teaching and learning.' In: Jack C. Richards; Willy A. Renandya (Eds.). Methodology in language teaching: An anthology of current Practice.. Cambridge: Cambridge University Press, 2002, p. 267-272. 
NATIONAL READING PANEL. Teaching children to read: an evidence-based assessment of the scientific research literature on reading and its implications for reading instructions. 2000. Disponível em:

https://www.nichd.nih.gov/sites/default/files/publications/pubs/nrp/Documents/report.pdf. acesso em 25 de maio de 2020.

PRINCE, P. Second language vocabulary learning: The role of context versus translations as a function of proficiency. Modern Language journal. n. 80, v. 4, p. 478-493, 1995.

READ, John. Research in teaching vocabulary. Annual Review of Applied Linguistics. v. 24, p. 146-161, 2004.

ROTTAVA, Lucia; DA SILVA, Antônio. M. Gêneros e registros em contexto de comunicação mediada eletronicamente: uma abordagem Sistêmico-Funcional da interação eletrônica de aprendizes de Português Língua Adicional. In: Rottava, L. et alii. (eds.). Reflexões em Linguística Aplicada: a formação de professores de línguas e a prática em sala de aula - caminhos e expectativas. Campinas, SP: Pontes Editores, 2015, p.199-225.

SEABROOK, R.; et.alii. Distributed and massed practice: from laboratory to classroom. Applied Cognitive Psychology. v. 19, p. 107-122, 2005.

SMITH, Steve; CONTI, Gianfranco. Teaching and learning vocabulary. The language teacher toolkit. p. 45-56, 2016.

SOBEL, H. S., et alii. Spacing effects in real-world classroom vocabulary learning. Applied Cognitive Psychology. v. 25, p. 763-767, 2011.

STAHL, S.A. Four problems with teaching word meanings (and what to do to make vocabulary an integral part of instruction). In: E.H. Hiebert; M.L. Kamil (Eds.), Teaching and learning vocabulary: Bringing research to practice. Mahwah, NJ: Erlbaum. 2005.

SUMERACKI, Megan, A.; WEINSTEIN, Yana. Optimising learning using retrieval practice. Impact: Journal of the Chartered College of Teaching. 2018. Disponível em:

https://impact.chartered.college/article/sumeracki-weinstein-optimising-learning-retrieval-pra ctice/ Acesso em 23 mar. de 2020.

WILLINGHAM, Daniel T. What will improve the student's memory? American Educator. p. 1725, 2008-2009.

Recebido em 01/06/2020. Aceito em 10/06/2020. 